\title{
PROPRIEDADES FÍSICAS DOS FRUTOS DE AMENDOIM DURANTE A SECAGEM ${ }^{1}$
}

\author{
WILLIAN DIAS ARAUJO ${ }^{2}$, ANDRÉ LUÍS DUARTE GONELI ${ }^{2}$, ROBERTO CARLOS ORLANDO $^{2}$, ELTON \\ APARECIDO SIQUEIRA MARTINS ${ }^{2}$, CESAR PEDRO HARTMANN FILHO ${ }^{2 *}$
}

\begin{abstract}
RESUMO - Objetivou-se com o presente estudo avaliar o efeito da secagem sobre as características físicas dos frutos de amendoim. Os frutos foram utilizados com um teor de água inicial de aproximadamente 0,63 decimal bs e submetidos à secagem com temperatura de $40{ }^{\circ} \mathrm{C}$. Foram determinadas as propriedades físicas, quais sejam: massa especifica aparente; massa específica unitária; porosidade; massa de mil grãos; esfericidade; circularidade; área projetada; área superficial; e a relação superfície/volume. Com base nos resultados encontrados conclui-se que a redução do teor de água proporcionou redução em todas as propriedades físicas dos frutos de amendoim, com exceção da relação superfície/volume, que tiveram seus valores aumentados com a redução do teor de água. A esfericidade, assim como a circularidade dos frutos de amendoim, tiveram seus valores reduzidos durante o processo de secagem.
\end{abstract}

Palavras-chave: Arachis hypogaea L.. Massa específica aparente. Porosidade. Esfericidade.

\section{PHYSICAL PROPERTIES OF PEANUT FRUITS DURING DRYING}

\begin{abstract}
The present work was accomplished with the objective of evaluating the drying effect on the peanut fruits physical properties. Peanut fruits with an initial moisture content of 0.63 decimal db were dried with a temperature of $40{ }^{\circ} \mathrm{C}$. Bulk density, true density, porosity, thousand-grain weight, sphericity, circularity, projected area, surface area and surface/volume ratio physical properties were determined. Based on these results, it is concluded that reducing the moisture content promotes reduction in all the physical properties of peanut fruits, except the surface/volume ratio that have their values increased with the moisture content reduction. The circularity as sphericity of the peanut fruit values was reduced during the drying process.
\end{abstract}

Keywords: Arachis hypogaea L.. Bulk density. Porosity. Sphericity.

\footnotetext{
*Autor para correspondência

${ }^{1}$ Recebido para publicação em 10/04/2014; aceito em 22/05/2015.

Parte do trabalho de Dissertação de Mestrado do Programa de Pós-Graduação em Agronomia da UFGD do primeiro autor.

${ }^{2}$ Faculdade de Ciências Agrárias, UFGD, Caixa Postal 533, 79804-970, Dourados (MS); williandias@casadalavoura.agr.br, andregoneli@ufgd.edu.br, robertoorlando@ufgd.edu.br, elton_asm@yahoo.com.br, cphartmann21@hotmail.com.
} 


\section{INTRODUÇ̃̃̃O}

A produção de alimentos tem sido cada vez mais exigente no que diz respeito à qualidade alimentícia. Produtos que possuam algum perigo em potencial de desenvolvimento e proliferação de pragas e doenças durante o cultivo e processamento devem ter toda a sua cadeia de produção e póscolheita rastreada a fim de serem tomadas medidas que contribuam para a redução e/ou eliminação de qualquer foco de deterioração e perda de qualidade. Culturas como o amendoim, onde o produto é colhido normalmente com elevado teor de água, se tornam ainda mais susceptíveis ao ataque de insetos e microrganismos, tornando-se fundamental o emprego do processo de secagem, considerando que a redução da quantidade de água do material decorrente desse processo irá reduzir atividades biológicas, bem comos mudanças químicas e físicas ocorridas durante o armazenamento.

Apesar da redução do teor de água influenciar possitivamente na tentativa de se manter a qualidade do produto após a colheita, mudanças nas caraterísitcas físicas dos materiais vegetais durante a secagem também são observadas (RESENDE et al., 2005). Logo, informações teóricas a respeito dessa singularidade são de suma importância para auxiliar no processamento pós-colheita, além de fornecer um conjunto de dados a engenheiros e projetistas que servirão de base na elaboração de máquinas, estruturas, processos de controle e proporcionar melhor eficiência de um equipamento ou operação. Assim, o conhecimento sobre as propriedades físicas do amendoim apresentadas durante a secagem é de fundamental importância para o correto manejo póscolheita da cultura, a fim de minimizar os custos de produção para maior competitividade e manutenção da qualidade do produto. Informações como tamanho, volume, porosidade e massa específica, entre outras, são ferramentas importantes no estudo envolvendo transferência de calor e massa e movimentação de ar em uma massa de grãos (GONELI et al., 2011).

Em geral, a forma do produto é uma das principais propriedades físicas influenciadas pela redução do teor de água durante a secagem. Além desta, tamanho, volume, área superficial, massa específica, porosidade, cor e aparência são algumas outras características físicas importantes em muitos problemas associados com a construção de uma máquina específica ou análise de comportamento de produtos (MOHSENIN, 1986), que também sofrem influência da redução do teor de água.

Deve-se ressaltar que o conhecimento das propriedades físicas constitui um importante e essencial conjunto de dados de engenharia para elaboração de máquinas, estruturas, processos e controle, na análise e determinação de eficiência de um equipamento ou operação, no desenvolvimento de novos produtos de origem animal e vegetal, bem como na avaliação e retenção de qualidade do produto final. Algumas informações básicas têm valor não somente para os engenheiros, como também para os cientistas e processadores de alimentos, estudos de reprodução de plantas, e outros cientistas que podem explorar essas propriedades e encontrar novos usos (MOHSENIN, 1986). Mata e Duarte (2002) admitem que o conhecimento da porosidade de uma massa de grãos é uma importante ferramenta no dimensionamento de silos, contêineres, caixas, embalagens e unidades transportadoras, além de estar contida dentro dos estudos da transferência de calor e massa, nos processos hidrodinâmicos, aerodinâmicos e termoelétricos. Sirisomboon et al. (2007) apresentaram as propriedades físicas, área superficial, área projetada, volume, circularidade e esfericidade dos frutos, nozes e sementes como sendo indispensáveis no dimensionamento de máquinas e equipamentos capazes de realizar o processo de descasque.

Muitos são os fatores que podem afetar as propriedades físicas, além do teor de água, sendo um deles o fato de alguns produtos agrícolas, como o fruto de amendoim, apresentar grãos no seu interior. Nesse sentido, inúmeros autores têm investigado as variações das propriedades físicas em função do teor de água e de outros fatores durante a secagem como, por exemplos, Siqueira et al. (2012a) trabalhando com frutos de pinhão manso, Lanaro et al. (2011) com grãos de feijão fradinho, Tavakoli et al. (2009) com cevada e Goneli et al. $(2008,2011)$ com frutos de mamona.

Considerando a importância do processo de secagem e da necessidade de informações para o desenvolvimento de equipamentos utilizados no processamento da cultura do amendoim, este trabalho foi realizado com o objetivo de determinar o efeito da variação do teor de água sobre as principais propriedades físicas dos frutos de amendoim.

\section{MATERIAL E MÉTODOS}

O presente trabalho foi realizado no Laboratório de Propriedades Físicas de Produtos Agrícolas da Faculdade de Ciências Agrárias, pertencente à Universidade Federal da Grande Dourados, localizada no município de Dourados (MS).

Foram utilizados frutos de amendoim da cultivar IAC 505, do grupo vegetativo e comercial Runner. Os frutos foram colhidos manualmente a fim de evitar qualquer tipo de influência ou dano físico. Após a colheita fora realizada a seleção, procurandose retirar todos aqueles que apresentassem defeitos, no intuito de evitar qualquer tipo de influência indesejável que pudesse atrapalhar ou interferir nos resultados da pesquisa. Inicialmente os frutos apresentaram valores com teor de água de aproximadamente 0,63 decimal (base seca, bs).

Os frutos de amendoim foram secos em uma estufa com ventilação forçada a uma temperatura de 
$40 \pm 1{ }^{\circ} \mathrm{C}$ e volume interno de 340 litros, sendo dispostas aleatoriamente cinco bandejas perfuradas com os referidos frutos. As bandejas continham produto suficiente para não se formar gradiente de umidade durante a secagem, bem como não faltar produto para nenhuma das determinações realizadas. A redução do teor de água foi acompanhada com o auxílio de uma balança com resolução de $0,01 \mathrm{~g}$ pelo método gravimétrico ou perda de massa (conhecendo-se o teor de água inicial do produto) até os frutos atingirem o teor de água final de aproximadamente 0,04 decimal (base seca, bs). Durante a secagem, para diferentes teores de água,o produto era retirado da estufa e homogeneizado para a determinação das propriedades físicas avaliadas. Os teores de água do produto foram determinados pelo método gravimétrico em estufa, a $105 \pm 1{ }^{\circ} \mathrm{C}$, durante $24 \mathrm{~h}$, em duas repetições (BRASIL, 2009).

A massa específica aparente $\left(\rho_{\mathrm{ap}}\right)$ foi determi-

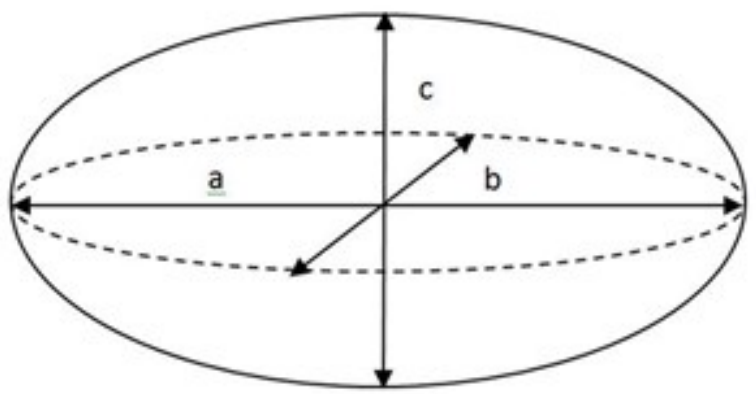

Figura 1. Representação esquematica dos eixos triaxiais do fruto de amendoim.

A determinação do volume $\left(\mathrm{V}_{\mathrm{g}}\right)$ para cada teor de água dos frutos de amendoim foi baseada na equação proposta por Mohsenin, (1986), Equação 1 mostrada a seguir:

$$
V_{g}=\frac{\pi(a b c)}{6}
$$

em que:

$\mathrm{V}_{\mathrm{g}}$ - volume, $\mathrm{mm}^{3}$.

a - comprimento, $\mathrm{mm}$;

b - largura, $\mathrm{mm}$;

c - espessura, mm.

A equação proposta por Mohsenin (1986), a qual visa a determinação do volume de produtos agrícolas (Equação 1), foi utilizada neste trabalho para o amendoim após testes preliminares com 200 frutos, divididos em 5 repetições. Após as dimensões características dos frutos serem determinadas cada repetição de 40 frutos fora imersa em tolueno em uma proveta graduada e seu volume real determinado pela diferença entre o volume total da proveta e o volume de tolueno gasto. Assim, foi possível verificar se os valores de volume calculados pela Equação 1 retornavam valores próximos ao real. Jain e Bal (1997) propuseram uma nova equação para deteminação do volume de produtos agrícolas considerando a forma do produto "cono-esféreica", desde então nada para os frutos de amendoim utilizando um recipiente em PVC, de formato cilíndrico com relação altura/diâmetro de 1:1, sendo o volume do recipiente de 2 L. A cada período de amostragem, determinado em função da perda de massa durante a secagem (método gravimétrico), o produto foi acondicionado no recipiente e somente então pôde-se realizar as leituras do volume. Posterioemente, o recipiente contendo os frutos foi pesado em uma balança com resolução de $0,01 \mathrm{~g}$.

$\mathrm{Na}$ determinação da massa específica real ou unitária 10 frutos foram escolhidos ao acaso e secos individualmente, sendo realizadas leituras periódicas durante a secagem. Com auxílio de um paquímetro digital com resolução de $0,01 \mathrm{~mm}$ foram realizadas medidas nas dimensões características dos produtos como: comprimento (a); largura (b); e espessura (c), conforme ilustrado na Figura 1.

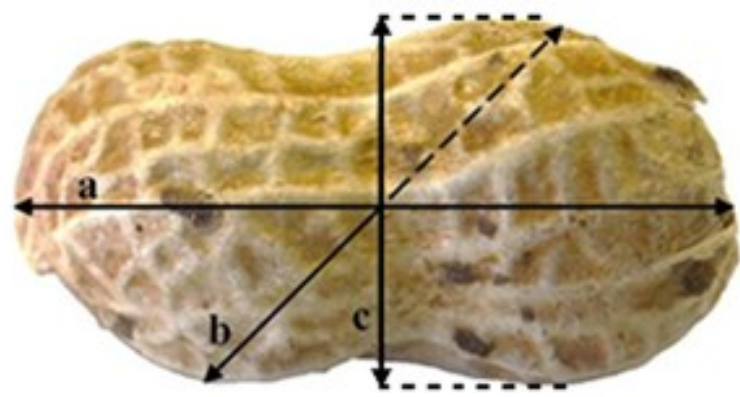

sendo utilizada por muitos pesquisadores nos mais diferentes produtos, incluindo o próprio amendoim (BALASUBRAMANIAN et al., 2011; PAYMAN et al., 2011). Apesar disso, o volume calculado pela equação proposta por aqueles autores retornavam valores de volume dos frutos de amendoim muito diferente do real determinado com tolueno nos testes preliminares, optando-se portanto pela Equação 1.

Após a determinação do volume os frutos de amendoim foram pesados utilizando-se uma balança com resolução de $0,001 \mathrm{~g}$ e a massa específica unitária determinada pela Equação 2.

$$
\rho_{\mathrm{u}}=\frac{\mathrm{m}_{\mathrm{g}}}{\mathrm{V}_{\mathrm{g}}}
$$

em que:

$\rho_{\mathrm{u}}$ - massa específica unitária, $\mathrm{kg} \mathrm{m}^{-3}$;

$\mathrm{m}_{\mathrm{g}}$ - massa de um fruto de amendoim, $\mathrm{g}$.

A porosidade da massa dos frutos de amendoim foi determinada pela relação:

$$
\varepsilon=\left[1-\frac{\rho_{\mathrm{ap}}}{\rho_{\mathrm{u}}}\right] 100
$$

em que:

$\varepsilon$ - porosidade, $\%$;

$\rho_{\text {ap }}$ - massa específica aparente, $\mathrm{kg} \mathrm{m}^{-3}$. 
A massa de 1000 de frutos foi determinada de acordo com a Regra de Análise de Sementes, a partir da escolha aleatória de 100 frutos de amendoim para cada teor de água ao longo da secagem. Utilizandose uma balança com resolução de $0,01 \mathrm{~g}$, em oito repetições, fora realizada a pesagem da massa do produto, sendo os resultados ajustados para 1000 frutos (BRASIL, 2009).

A forma dos frutos de amendoim foi caracterizada pela esfericidade e circularidade. A esfericidade $\left(E_{s}\right)$ foi calculada utilizando-se a expressão proposta por Mohsenin (1986), qual seja:

$$
E_{s}=\left[\frac{(a b c)^{1 / 3}}{a}\right] 100
$$

em que:

$\mathrm{E}_{\mathrm{s}}$ : esfericidade, $\%$.

A circularidade $(\mathrm{C})$ dos produtos foi determinada pela expressão (MOHSENIN, 1986):

$$
C=\left(\frac{b}{a}\right) 100
$$

em que:

C: circularidade, $\%$.

A área projetada (Ap), em $\mathrm{mm}^{2}$, dos frutos de amendoim foi determinada pela expressão:

$$
A_{p}=\frac{\pi a b}{4}
$$

em que:

$\mathrm{A}_{\mathrm{p}}$ : Área projetada, $\mathrm{mm}^{2}$.

A área superficial (S), em $\mathrm{mm}^{2}$, dos frutos de amendoim foi calculada pelo modelo de Mohsenin (1986), realizando-se ajustes nas dimensões características do produto, auxiliado da seguinte expressão:

$$
S=\frac{\pi B^{2}}{2}+\frac{\pi a B}{2 E} \operatorname{sen}^{-1} E
$$

onde:

$$
\begin{gathered}
B=(b c)^{1 / 2} \\
E=\sqrt{1-\left(\frac{B}{a}\right)^{2}}
\end{gathered}
$$

em que:

$\mathrm{S}$ - área superficial, $\mathrm{mm}^{2}$.

$\mathrm{B}$ - média geométrica entre o comprimento e a largu-

ra do fruto, $\mathrm{mm}$;

E - excentricidade.
Outro método empregado para se calcular a área superficial dos frutos de amendoim foi a equação da superfície da esfera, levando-se em consideração o diâmetro geométrico do produto $\left(\mathrm{D}_{\mathrm{g}}\right)$, equação esta também utilizada por Tunde-Akintunde e Akintunde (2004).

$$
S=\pi\left(D_{g}\right)^{2}
$$

onde:

$$
D_{g}=(a b c)^{1 / 3}
$$

A relação entre a área superficial $(\mathrm{S})$ e a massa dos frutos de amendoim foi determinada segundo a equação (MOHSENIN, 1986):

$$
\mathrm{S}=\xi \mathrm{W}^{\mathrm{d}}
$$

em que:

$\mathrm{S}$ - área superficial, $\mathrm{mm}^{2}$;

$\mathrm{D}_{\mathrm{g}}$ - diâmetro médio geométrico, mm;

$\xi$ e d - constantes da relação, adimensionais;

$\mathrm{W}$ - massa, g.

A relação superfície/volume (SV) dos frutos de amendoim foi calculada por meio da expressão:

$$
\mathrm{SV}=\frac{\mathrm{S}}{\mathrm{V}_{\mathrm{g}}}
$$

Os dados experimentais referentes às propriedades físicas dos frutos de amendoim foram submetidos a análise de regressão linear. Para o ajuste dos modelos de regressão utilizou-se o programa computacional STATISTICA $7.0^{\circledR}$ (STATSOFT, INC., 2007). O nível de significância da regressão, juntamente com os valores do coeficiente de determinação $\left(\mathrm{R}^{2}\right)$, pelo teste $t$, serviu de parâmetros para seleção do modelo.

\section{RESULTADOS E DISCUSSÃO}

Na Figura 2 são apresentados os valores experimentais e estimados da massa específica aparente dos frutos de amendoim para diferentes teores de água durante a secagem.

Verifica-se na Figura 2 que houve redução na massa específica aparente dos frutos de amendoim de forma linear ao longo da secagem, contrariando a maioria dos produtos agrícola. Em geral, como a massa específica é uma relação entre a massa e o volume do produto durante a secagem a taxa de redução do volume é maior do que a taxa de perda de massa devido a redução do teor de água. Assim, para a maioria dos produtos agrícolas ocorre aumento da massa específica aparente com a redução do teor de 
água, diferente do que ocorre com os frutos de amendoim, tendo em vista a baixa redução de seu volume durante a secagem. Razavi et al. (2007), trabalhando com pistache, verificaram resultados semelhantes aos observados no presente estudo.

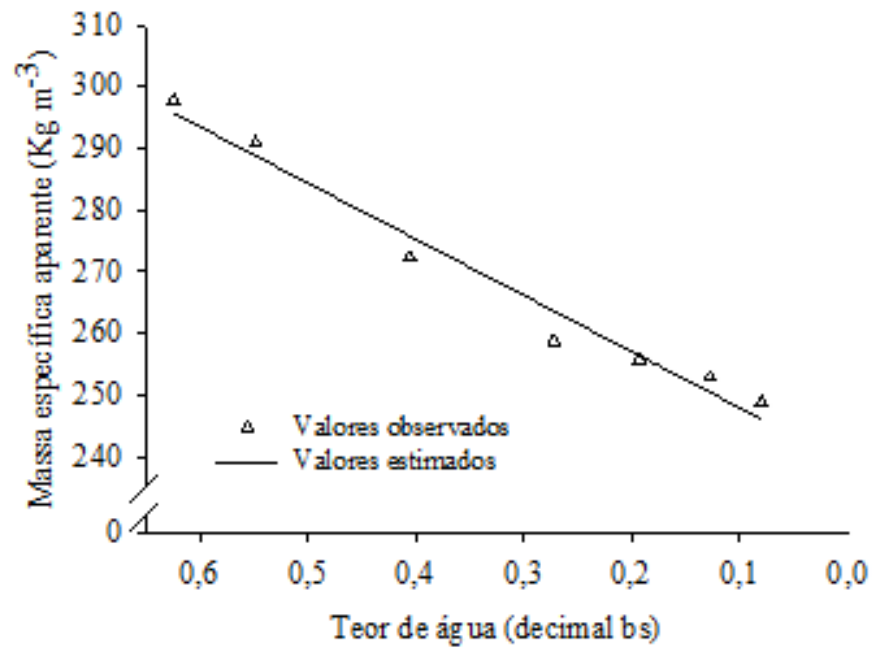

Figura 2. Valores observados e estimados da massa específica aparente dos frutos de amendoim em função do teor de água.

Observa-se também na Figura 2 que os valores experimentais da massa específica aparente dos frutos de amendoim variaram de 297 a $248 \mathrm{~kg} \mathrm{~m}^{-3}$ em uma faixa de teor de água de 0,63 a 0,04 decimal (bs), respectivamente. Nota-se, também, que a redução dos valores da massa especifica aparente pode ser satisfatoriamente representado por um modelo de regressão linear simples (Tabela 1). Siqueira et al. (2012a) encontraram resultados semelhantes a estes, no qual houve redução nos valores de massa especí- fica aparente dos frutos de pinhão-manso.

$\mathrm{Na}$ Tabela 1 estão alocados os modelos ajustados aos dados observados para as diversas propriedades físicas estudadas dos frutos de amendoim em função do teor de água. Esses modelos se mostram adequados ao estimar as propriedades físicas dos frutos de amendoim, apresentando elevados valores do coeficiente de determinação $\left(\mathrm{R}^{2}\right)$ e significância satisfatória dos modelos.

Tabela 1. Equações ajustadas aos valores das propriedades físicas dos frutos de amendoim em função do teor de água.

\begin{tabular}{ccccc}
\hline Variável analisada & Modelo & $\begin{array}{c}\mathrm{R}^{2} \\
\text { (decimal) }\end{array}$ & $\mathrm{F}$ & $\mathrm{P}_{\text {level }}$ \\
\hline Massa específica aparente & $\rho_{\mathrm{a}}=238,7430+91,3798^{*} \mathrm{M}$ & 0,9745 & 191,4523 & $<0,0001$ \\
Massa específica unitária & $\rho_{u}=610,0642+360,1568^{*} \mathrm{M}$ & 0,9934 & 757,0493 & $<0,0001$ \\
Porosidade & $\varepsilon=61,1113+5,6972^{*} \mathrm{M}$ & 0,9480 & 91,1380 & $<0,0002$ \\
Massa de mil frutos & $\mathrm{M}_{1000}=1070,9538+956,1933^{*} \mathrm{M}$ & 0,9822 & 440,8948 & $<0,0001$ \\
Área projetada & $\mathrm{A}_{\mathrm{P}}=344,5888+60,7847^{*} \mathrm{M}$ & 0,9470 & 89,3446 & $<0,0002$ \\
Área superficial ${ }^{1}$ & $\mathrm{~S}=1025,2980+165,8699^{*} \mathrm{M}$ & 0,9659 & 141,6356 & $<0,0001$ \\
Área superficial ${ }^{2}$ & $\mathrm{~S}=883,0712+143,7282^{*} \mathrm{M}$ & 0,9665 & 144,4021 & $<0,0001$ \\
Relação superfície/volume & $\mathrm{S} / \mathrm{V}=0,2859+\left(-0,0213^{*} \mathrm{M}\right)$ & 0,9584 & 115,1690 & $<0,0001$ \\
Relação superfície/massa & $\mathrm{S} / \mathrm{M}=\left(770,3594^{*} \mathrm{~W}^{0,2133}\right)$ & 0,9744 & 190,5769 & $<0,0001$
\end{tabular}

${ }^{1}$ Área superficial calculada pela Equação 10 (Tunde-Akintunde e Akintunde, 2004);

${ }^{2}$ Área superficial calculada pela Equação 7 (Mohsenin, 1986);

$\mathrm{M}=$ teor de água (decimal bs);

* Significância a $1 \%$, teste $\mathrm{t}$. 
Assim como a massa específica aparente, os valores da massa específica unitária dos frutos de amendoim também sofreram redução, conforme a redução do teor de água (Figura 3).

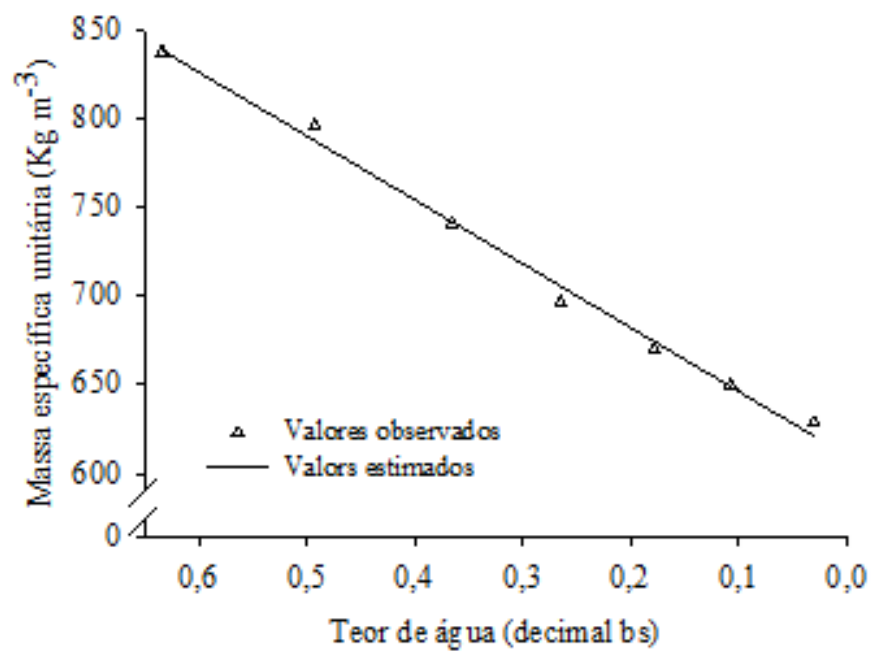

Figura 3. Valores observados e estimados da massa específica unitária dos frutos de amendoim em função do teor de água.

Esses resultados (Figura 3) podem estar relacionados ao fato de que a maior parte dos frutos de amendoim serem compostos por grãos e seu encolhimento não é proporcional a perda de massa durante o processo de secagem. Resultados semelhantes foram observados e relatados por outros pesquisadores ao trabalharem com frutos de mamona (GONELI et al., 2008), pistache (RAZAVI et al., 2007), arroz em casca (REDDY; CHAKRAVERTY, 2004) e sementes de abóbora (PAKSOY; AYDIN, 2004).
Os valores experimentais da massa específica unitária dos frutos de amendoim variaram de 837 a $628 \mathrm{~kg} \mathrm{~m}^{-3}$ (Figura 3) para a faixa de teor de água de 0,63 a 0,04 decimal (bs), respectivamente. Para estes valores fora obtido um coeficiente de determinação satisfatório com modelo de regressão linear (Tabela 1).

$\mathrm{Na}$ Figura 4 estão apresentados os valores experimentais e estimados da porcentagem de espaços vazios na massa dos frutos de amendoim em função do teor de água (decimal bs).

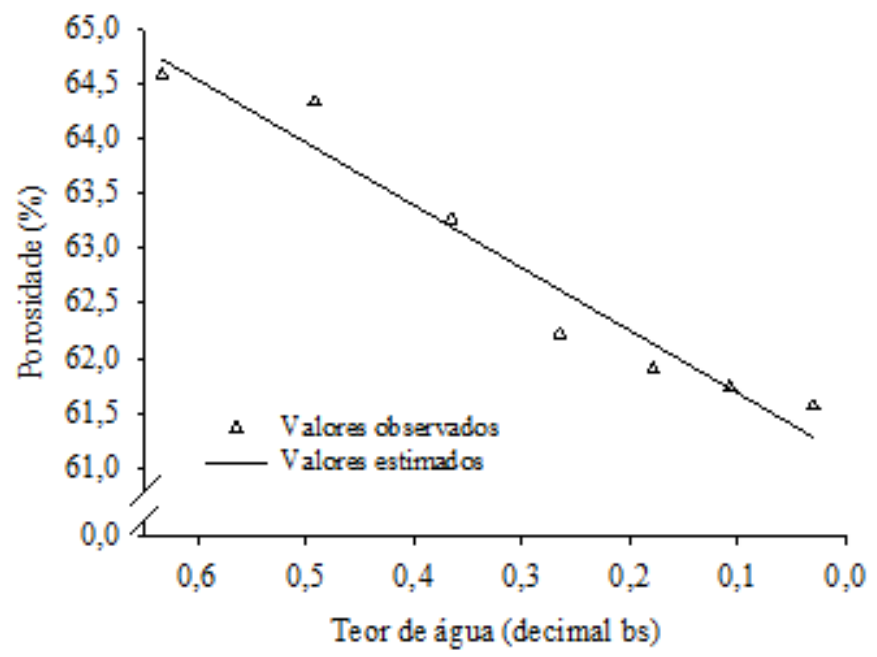

Figura 4. Valores observados e estimados da porosidade dos frutos de amendoim em função do teor de água.

Observando a Figura 4 nota-se que a porosidade da massa dos frutos de amendoim apresentou comportamento semelhante ao encontrado para a maioria dos produtos agrícolas, onde seus valores foram reduzidos com o decréscimo do teor de água (SIQUEIRA et al., 2012a; GONELI et al., 2008; FA-
THOLLAHZADEH et al., 2008; DURSUN et al., 2007; KARABABA, 2006). Ao decorrer do processo de secagem tornou-se possível observar uma contração volumétrica gradativa dos frutos de amendoim, proporcionando a redução dos espaços intergranulares, em que por meio da determinação indireta da 
porosidade pode-se chegar aos resultados encontrados no presente estudo. A porosidade da massa dos frutos de amendoim foi de 64,57 para $61,53 \%$ em uma faixa de teor de água de 0,63 a 0,04 decimal (bs). Essa pequena variação da porosidade esteja provavelmente relacionada à reduzida capacidade dos compostos estruturais que formam a casca dos frutos de amendoim em diminuir o seu volume.
Nota-se ainda que a redução dos valores da porosidade da massa dos frutos de amendoim (Figura 4) pode ser representada satisfatoriamente por meio de um modelo de regressão linear simples (Tabela 1).

Na Figura 5 são apresentados os valores observados e estimados dos efeitos da variação do teor de água na massa de mil frutos de amendoim em função da secagem.

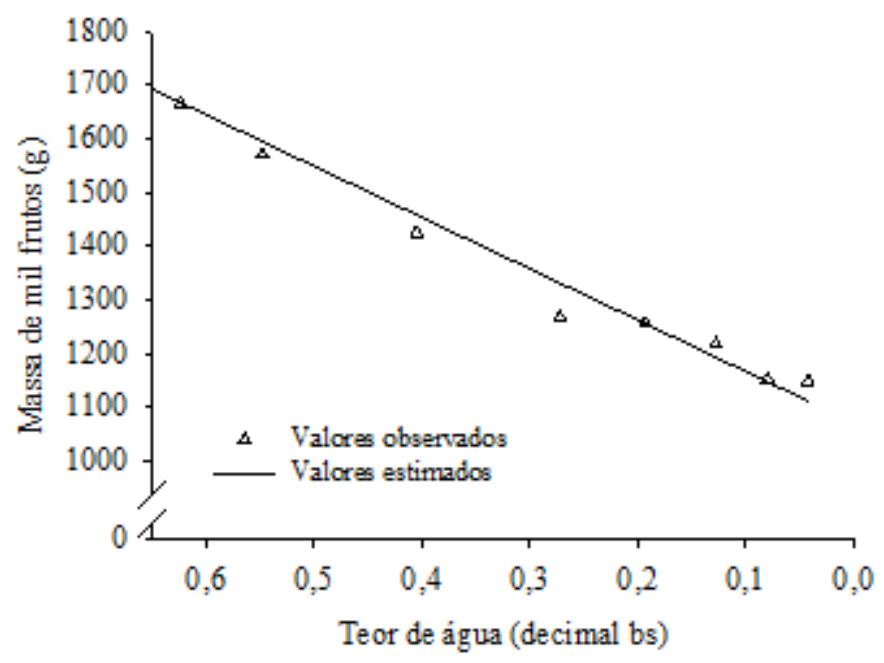

Figura 5. Valores observados e estimados da massa de mil frutos de amendoim em função do teor de água.

Pode-se observar na Figura 5 que a redução do teor de água do produto acaba proporcionando também uma redução dos valores da massa de mil frutos. Verifica-se ainda que conforme o teor de água é reduzido a massa de mil frutos de amendoim varia de 1786 a 1147 g. Os resultados deste trabalho corroboram com os resultados encontrados por outros pesquisadores trabalhando com diversos produtos (BANDE et al., 2012; GONELI et al., 2008; AYDIN, 2007; DURSUN et al., 2007). O modelo linear foi o que melhor se adequou aos dados experimentais, apresentando elevado nível de significância e elevado valor do coeficiente de determinação (Tabela 1).

$\mathrm{Na}$ Tabela 2 são apresentados os valores das dimensões características $(a, b, c)$, o diâmetro geométrico médio $\left(\mathrm{D}_{\mathrm{g}}\right)$, o volume $(\mathrm{V})$, os índices de contração das dimensões características $\left(\mathrm{a} / \mathrm{a}_{0}, \mathrm{~b} / \mathrm{b}_{0}\right.$ e $\mathrm{c} /$ $\mathrm{c}_{0}$ ), da circularidade (C) e da esfericidade (E) dos frutos de amendoim em função da secagem.

Tabela 2. Dimensões características (a, b, c, $\left.D_{g}\right)$, volume $(V)$, índices de contração $\left(a / a_{0}, b / b_{0}\right.$ e c/c $\left.c_{0}\right)$, circularidade $(C)$ e esfericidade (E) dos frutos de amendoim em função do teor de água.

\begin{tabular}{|c|c|c|c|c|c|c|c|c|c|c|}
\hline \multirow{2}{*}{$\begin{array}{l}\text { Teor de } \\
\text { água } \\
\text { (bs) }\end{array}$} & \multicolumn{4}{|c|}{ Dimensões características (mm) } & \multirow{2}{*}{$\begin{array}{l}\text { Volume } \\
\left(\mathrm{mm}^{3}\right)\end{array}$} & \multirow[b]{2}{*}{$\mathrm{a} / \mathrm{a}_{\mathrm{o}}$} & \multirow[b]{2}{*}{$\mathrm{b} / \mathrm{b}_{\mathrm{o}}$} & \multirow[b]{2}{*}{$\mathrm{c} / \mathrm{c}_{\mathrm{o}}$} & \multirow{2}{*}{$\begin{array}{l}\mathrm{C} \\
(\%)\end{array}$} & \multirow{2}{*}{$\begin{array}{c}\mathrm{E} \\
(\%)\end{array}$} \\
\hline & $\mathrm{a}$ & $\mathrm{b}$ & $\mathrm{c}$ & $\mathrm{D}_{\mathrm{g}}$ & & & & & & \\
\hline 0,63 & 32,67 & 14,82 & 14,03 & 18,94 & 3556,78 & 1,00 & 1,00 & 1,00 & 45,36 & 57,97 \\
\hline 0,49 & 32,50 & 14,64 & 13,81 & 18,73 & 3441,24 & 0,99 & 0,99 & 0,98 & 45,05 & 57,63 \\
\hline 0,36 & 32,36 & 14,55 & 13,74 & 18,64 & 3389,09 & 0,99 & 0,98 & 0,98 & 44,96 & 57,59 \\
\hline 0,26 & 32,21 & 14,45 & 13,71 & 18,54 & 3338,71 & 0,99 & 0,97 & 0,98 & 44,86 & 57,58 \\
\hline 0,17 & 31,93 & 14,23 & 13,62 & 18,36 & 3239,87 & 0,98 & 0,96 & 0,97 & 44,57 & 57,50 \\
\hline 0,10 & 31,59 & 14,03 & 13,52 & 18,16 & 3135,84 & 0,97 & 0,95 & 0,96 & 44,40 & 57,49 \\
\hline 0,03 & 31,45 & 13,93 & 13,46 & 18,07 & 3088,99 & 0,96 & 0,94 & 0,96 & 44,29 & 57,45 \\
\hline
\end{tabular}

De acordo com a Tabela 2 é possível verificar que as dimensões características (comprimento, largura e espessura) dos frutos de amendoim apresentaram comportamento semelhante, em que os valores foram reduzidos com o decréscimo do teor de água devido a secagem. A partir da variação das dimen- sões do produto com a redução do teor de água projetistas de secadores podem aperfeiçoar e/ou projetar um sistema de secagem mais adequado à secagem, levando-se em consideração fatores como direção do fluxo de ar, movimentação do produto no secador, dentre outros parâmetros e processos. Resultados 
semelhantes a esses foram relatados por Goneli et al. (2011), Razavi et al. (2007), Corrêa et al. (2006) e Resende et al. (2005). Além disso, os dados deixam evidente que o volume dos frutos de amendoim tem seus valores reduzidos com a redução do teor de água, de forma gradual. Siqueira et al. (2012b), trabalhando com pinhão-manso, observaram resultados semelhante aquele verificado neste trabalho.

Observando a Tabela 2 é possível verificar ainda que os frutos de amendoim, em média, apresentaram maior redução no índice de contração da sua largura (b), sendo essa redução de $6 \%$, se comparado ao comprimento (a) e a espessura (c), ambas com $4 \%$, variando o teor de água do produto de 0,63 a 0,04 decimal (bs). Além disso, pode-se afirmar que as magnitudes dos índices de contração das dimensões dos frutos de amendoim sofreram pequena influência em função da redução do teor de água durante a secagem, fato este relacionando, provavelmente, com a composição química do pericarpo ou casca do fruto. Goneli et al. (2011) e Resende et al.
(2005) também observaram comportamento semelhante aos encontrados no presente estudo.

Ainda de acordo com a Tabela 2 verifica-se uma pequena redução na magnitude dos valores de circularidade e esfericidade com a redução do teor de água devido a secagem dos frutos de amendoim. Esses resultados são explicados devido a contração uniforme das principais dimensões que compõem os frutos. Goneli et al. (2011), trabalhando com frutos de mamona, também observaram resultados semelhantes, nos quais a circularidade e a esfericidade apresentaram pequenas variações em seus valores. Tanto a circularidade quanto a esfericidade mantiveram seus valores abaixo de $60 \%$, cujos valores tornam os frutos de amendoim classificados como não circulares e não esféricos.

Na Figura 6 são encontrados os valores da área projetada dos frutos de amendoim em função da redução do teor de água (decimal, bs) durante a secagem.

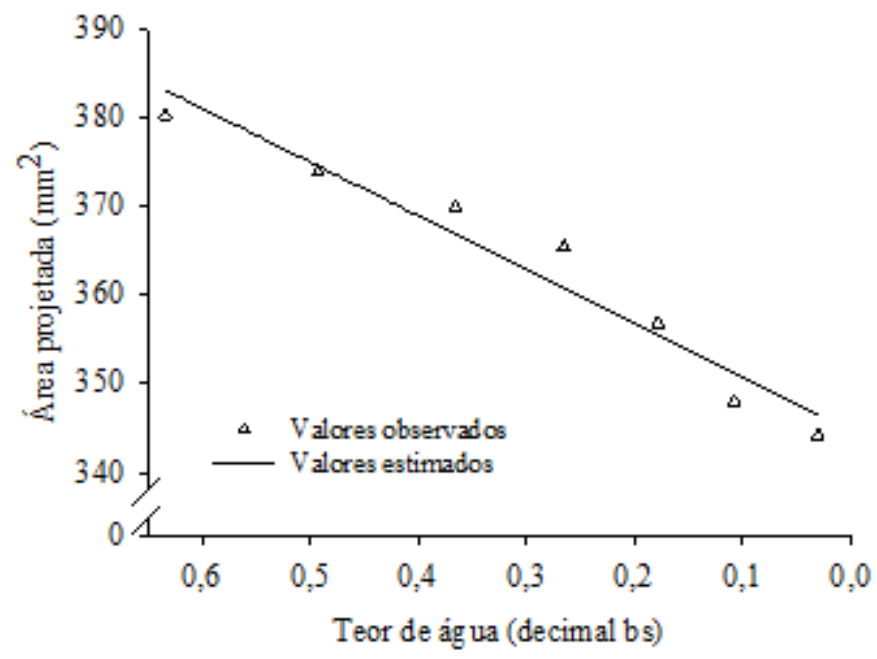

Figura 6. Valores observados e estimados da área projetada dos frutos de amendoim em função do teor de água.

Analisando o resultado (Figura 6) pode-se evidenciar que houve redução nos valores da área projetada dos frutos de amendoim com o decréscimo do teor de água. A diminuição dos valores da área projetada está relacionada com a redução do volume dos frutos de amendoim ao longo do processo de secagem, podendo afetar a passagem de ar em uma massa de frutos de amendoim durante seu processamento e/ou secagem. Esse fenômeno também foi observado em outros trabalhos (SIQUEIRA et al., 2012b; GUEDES et al., 2011; GONELI et al., 2008; YALÇIN et al., 2007; AYDIN, 2007; COŞKUNER e KARABABA, 2007). Nota-se que a área projetada dos frutos de amendoim (Figura 6) variou de 380,21 a $344,16 \mathrm{~mm}^{2}$ para a faixa de teor de água de 0,63 a 0,04 decimal (bs), respectivamente, sendo esse fenômeno satisfatoriamente representado por um modelo de regressão linear simples (Tabela 1).
São apresentados na Figura 7 os valores observados e estimados da relação superfície/volume dos frutos de amendoim em função da secagem.

É observável na Figura 7 que os valores da relação superfície/volume dos frutos de amendoim têm suas magnitudes elevadas com a redução do teor de água durante o processo de secagem. Quanto maior o tamanho do organismo menor é sua relação superfície/volume, consequentemente menor também será a dissipação de calor em sua superfície e menor o seu metabolismo. Dessa forma, além da proteção a casca permite que o amendoim tenha uma menor perda por respiração durante o processamento, em comparação com os grãos processados já descascados. Assim, o aumento dos valores da relação superfície/volume com a redução do teor de água indicam redução no tamanho dos frutos com a secagem. Esses resultados assemelham-se com os observados por Siqueira et al. (2012b), quando na ocasião trabalha- 
vam com frutos de pinhão-manso. Pode-se dizer que o fenômeno em estudo pode ser satisfatoriamente representado por um modelo de regressão linear simples, no qual sua equação é apresentada na Tabela 1.
A relação superfície volume dos frutos de amendoim variou aproximadamente de 0,27 a $0,28 \mathrm{~mm}^{-1}$ para a faixa de teor de 0,63 a 0,04 decimal (bs), respectivamente.

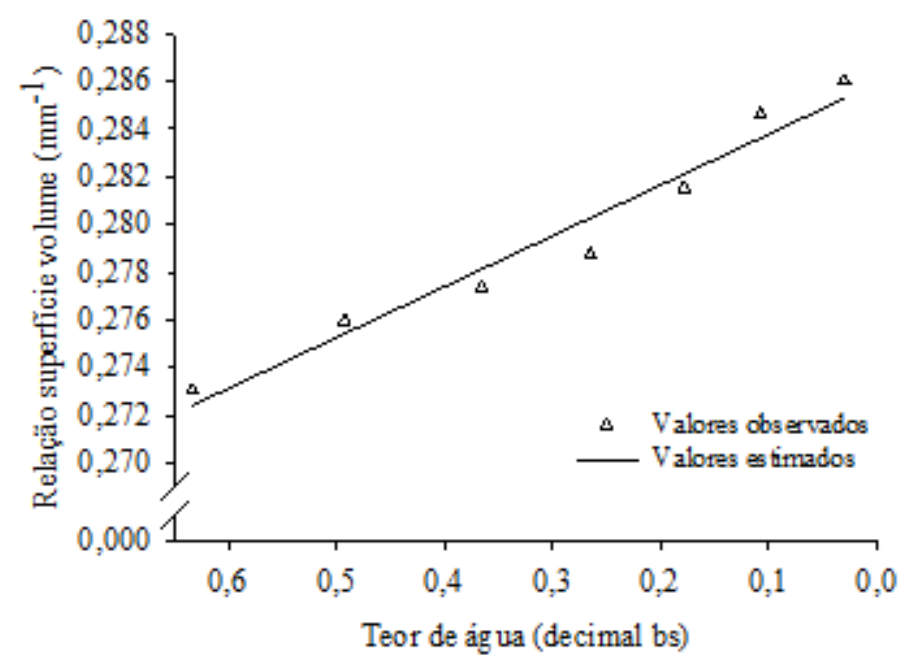

Figura 7. Relação superfície volume dos frutos de amendoim em função do teor de água em estudo.

São apresentados na Figura 8 os valores observados e estimados da área superficial dos frutos de amendoim em função da secagem, utilizando modelos propostos por diferentes autores.

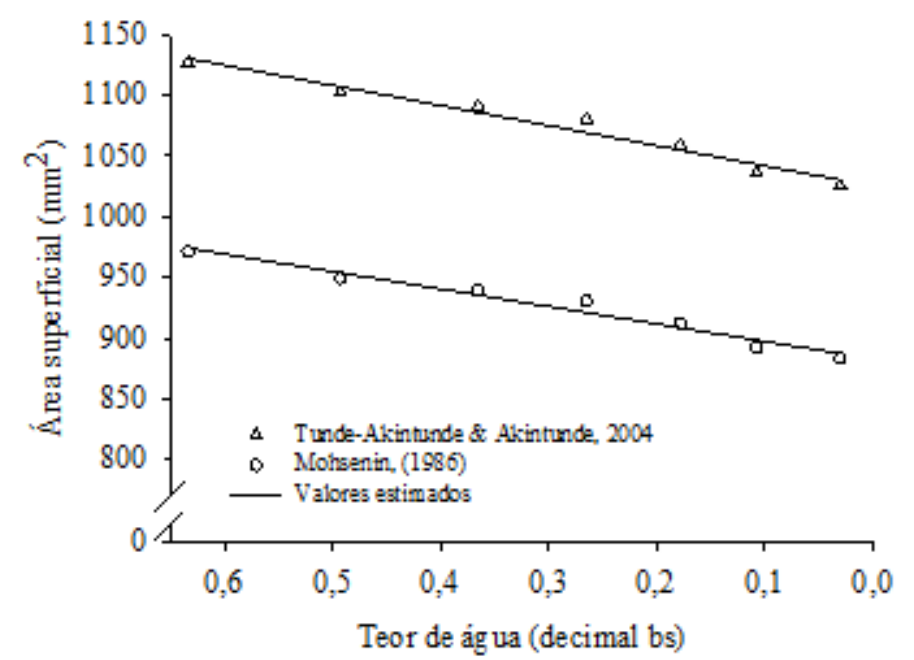

Figura 8. Valores observados e estimados da área superficial dos frutos de amendoim em função do teor de água.

Obsevando a Figura 8 verifica-se que em ambos os modelos utilizados houve redução dos valores da área superficial dos frutos de amendoim com a redução do teor de água, uma vez que a equação da superfície da esfera admite apenas o diâmetro médio como parâmetro para a obtenção dos valores da área superficial dos frutos de amendoim, o que torna duvidoso a precisão dos valores, haja vista a irregularidade e conformidade do produto. Sendo assim, observa-se certa discrepância entre os valores dos modelos empregados para uma mesma faixa de teor de água. Provavelmente esse fenômeno está ligado ao fato de que o modelo de Mohsenin (1986) apresenta ajustes matemáticos nas principais dimensões do produto, corroborando para valores próximos do real. Independentemente da equação empregada houve redução ao redor de $9 \%$ da área superficial dos frutos de amendoim em relação aos seus valores iniciais. A metodologia proposta por Mohsenin (1986) realiza ajustes nas dimensões características do produto (Equações 7, 8 e 9), o que supõe que os valores de área superficial obtidos por essa equação são mais próximos do real e, consequentemente, a mais recomendada para a determinação da área supericial dos frutos de amendoim. A redução dos valores da área superficial em função da redução do teor de água do 
produto também foi observada por diferentes autores (SIQUEIRA et al., 2012b; GONELI et al., 2008; RAZAVI et al., 2007).

O modelo de representação da área superficial em função da massa dos frutos de amendoim, proposto por Mohsenin (1986), foi satisfatoriamente ajustados aos dados experimentais (Tabela 1) obtidos para os frutos de amendoim, apresentando valor elevado do coeficiente de determinação, e assemelhando-se aos resultados encontrados por Goneli et al. (2008), trabalhando com frutos de mamona. A partir dessa relação torna-se possível estimar a área superficial dos frutos de amendoim, em $\mathrm{mm}^{2}$, a partir de dados de massa unitária, em gramas, dentro da faixa de teor de água estudada, permitindo uma maior facilidade para projetistas de equipamentos destinados a pós-colheita do produto que necessitem dessas informações

\section{CONCLUSÃ̃o}

Em função dos resultados obtidos neste trabalho pode-se concluir que a redução do teor de água devido o processo de secagem ocasionou variação na magnitude de todas as propriedades físicas avaliadas. Com a redução do teor de água houve redução na massa específica aparente e unitária, na porosidade, na massa de mil frutos, nas dimensões características, na área projetada, área superficial, circularidade e a esfericidade dos frutos de amendoim durante a secagem. A equação de Mohsenin utilizada para representar a relação entre a área superficial e a massa dos frutos de amendoim pode ser aplicada no presente estudo. No que toca à relação superfície/volume dos frutos de amendoim ela aumenta com a redução do teor de água.

\section{AGRADECIMENTOS}

À Capes e à Fundect pelo apoio financeiro para a realização desta pesquisa.

\section{REFERÊNCIAS}

AYDIN, C. Some engineering properties of peanut and kernel. Journal of Food Engineering, London, v. 79, n. 3 , p. $810-816,2007$.

BALASUBRAMANIAN, S.; SHARMA, R.; SARDANA, V. Studies on some engineering properties of peanut pod and kernel. Journal of Agricultural Engineering, Pavia, v. 48, n. 2, p. 38-42, 2011.

BANDE, Y. M. et al. Moisture-dependent physical and compression of bitter melon (Citrullus colocynthis lanatus) seeds. International Journal of Agri- cultural Research, Hamedan, v. 7, n. 5, p. 243-254, 2012.

BRASIL. Ministério da Agricultura, Pecuária e Abastecimento. Secretaria de Defesa Agropecuária. Regras para análise de sementes, Brasília: MAPA/ ACS, 2009. 399p.

CORRÊA, P. C. et al. Determinação e modelagem das propriedades físicas e da contração volumétrica do trigo, durante a secagem. Revista Brasileira de Engenharia Agrícola e Ambiental, Campina Grande, v. 10, n. 3, p. 665-670, 2006.

COŞKUNER, Y.; KARABABA, E. Physical properties of coriander seeds (Coriandrum sativum L.). Journal of Food Engineering, Çiftlikköy Mersin, v. 80 , n. 2, p. 408-416, 2007.

DURSUN, I.; TUĞRUL, K. M.; DURSUN, E. Some physical properties of sugarbeet seed. Journal of Stored Products Research, Ankara, v. 43, n. 2, p. 149-155, 2007.

FATHOLLAHZADEH, H. et al. Effect of moisture content on some physical properties of Apricot kernel (C.V. Sonnati Salmas). Agricultural Engineering International: CIGR Ejournal, Karaj, v. 10, n. 8 , p. $1-14,2008$.

GONELI, A. L. D. et al. Propriedades físicas dos frutos de mamona durante a secagem. Revista Brasileira de Armazenamento, Viçosa, v. 33, n. 2, p. 148 $-155,2008$.

GONELI, A. L. D. et al. Contração volumétrica e forma dos frutos de mamona durante a secagem. Acta Scientiarum. Agronomy, Maringá, v. 33, n. 1, p. 1-8, 2011.

GUEDES, M. A. et al. Caracterização física de grãos de soja utilizando processamento digital de imagens. Revista Brasileira de Produtos Agroindustriais, Campina Grande, v. 13, n. 3, p. 279-294, 2011.

JAIN, R. K.; BAL, S. Properties of pearl millet. Journal of Agricultural Engineering Research, London, v. 66, n. 2, p. 85-91, 1997.

KARABABA, E. Physical properties of popcorn kernels. Journal of Food Engineering, London, v. 72, n. 1 , p. $100-107,2006$.

LANARO, N. D. et al. Determinação de propriedades físicas do feijão fradinho. Revista Brasileira de Produtos Agroindustriais, Campina Grande, v. 13, n. 1 , p. $27-35,2011$.

MATA, M. E. R. M. C.; DUARTE, M. E. M. Porosidade intergranular de produtos agrícolas. Revista 
Brasileira de Produtos Agroindustriais, Campina Grande, v. 4, n. 1, p. 79-93, 2002.

MOSHENIN, N. N. Physical properties of plant and animal materials, New York: Gordon and Breach Publishers, 1986, p. 841.

PAKSOY, M.; AYDIN, C. Some physical properties of edible squash (Cucurbita pepo L.) seeds. Journal of Food Engineering, London, v. 65, n. 2, p. 225 231, 2004.

PAYMAN, S. H. et al. Effect of moisture content on some engineering properties of peanut varieties. Journal of Food, Agriculture \& Environment, Helsinki, v. 9, n. 3 e 4, p. 326-331, 2011.

RAZAVI, S. M. A. et al.The physical properties of pistachio nut and kernel as a function of moisture content and variety: Part I. Geometrical properties. Journal of Food Engineering, London, v. 81, n. 1, p. 209-217, 2007.

REDDY, B. S.; CHAKRAVERTY, A. Physical properties of raw and parboiled paddy. Biosystems Engineering, London, v. 88, n. 4, p. 461-466, 2004.

RESENDE, O. et al. Forma, tamanho e contração volumétrica do feijão (Phaseolus vulgaris L.) durante a secagem. Revista Brasileira de Produtos Agroindustriais, Campina Grande, v. 7, n. 1, p. 1524, 2005.

SIQUEIRA, V. C.; RESENDE, O.; CHAVES, T. H. Propriedades físicas dos frutos de pinhão-manso durante a secagem. Global Science and Technology, Rio Verde, v. 5, n. 1, p. 83-92, 2012a.

SIQUEIRA, V. C. et al. Forma e tamanho dos frutos de pinhão-manso durante a secagem em cinco condições de ar. Revista Brasileira de Engenharia Agrícola e Ambiental, Campina Grande, v. 16, n. 8, p. 864-870, 2012b.

SIRISOMBOON, P. et al. Physical and mechanical properties of Jatropha curcas L. fruits, nuts and kernels. Biosystems Engineering, London, v. 97, n. 2, p. 201-207, 2007.

STATSOFT, INC. Statistica (Data Analysis Software System), Version 7, 2007.

TAVAKOLI, M. et al. Moisture-dependent physical properties of barley grains. International Journal of Agricultural and Biological Engineering, Beijing, v. 2 , n. 4 , p. $84-91,2009$.

TUNDE-AKINNTUNDE, T. Y.; AKINTUNDE, B. O. Some physical properties of sesame seed. Biosys- tems Engineering, London, v. 88, n. 1, p. 127-129, 2004.

YALÇIN, İ.; ÖZARSLAN, C.; AKBAŞ, T. Physical properties of pea (Pisum sativum) seed. Journal of Food Engineering, London, v. 79, n. 2, p. 731-735, 2007. 